\title{
El español en los Andes coloniales: textos, autores y discursos
}

CuAndo hace más de 500 AÑos la LENGUA española se expandió hacia sus colonias en América, en el camino que parecía recorrer su historia se abrió de pronto un atajo hacia un fascinante desvío. En ese nuevo trecho tomado hacia las Indias, la lengua de los reyes católicos se toparía con las más diversas culturas y sus lenguas, varias de las cuales se desarrollaban en la imponente geografía de los Andes sudamericanos. Dicha verdad despertó desde su nacimiento el interés práctico de los evangelizadores, provenientes de una Europa humanista que ya había iniciado la producción de gramáticas de las lenguas romances y de otras lenguas exóticas. Por lo demás, las lenguas amerindias siguieron avivando la agudeza en la mirada de los estudiosos de los tiempos posteriores. Destacados lingüistas, filólogos e historiadores de la lengua y la literatura, desde distintas universidades en el mundo, han echado también una mirada a esa parte de la historia del español. A ellos se han sumado además especialistas de otras disciplinas, americanistas y peruanistas, quienes con sus investigaciones han ido demostrando la relevancia del trabajo interdisciplinario. En esa corriente no han 
faltado representantes de la academia alemana y profesionales formados en ella, algunos de los cuales en esta oportunidad han tenido a bien acudir a la convocatoria del Instituto de Pastoral Andina para contribuir con el presente número de su revista institucional Allpanchis.

El español que se habló en los Andes del Perú en los siglos XVI y XVII ha sido uno de los temas de estudio de un grupo de investigadores vinculados a la Ludwig-Maximilian-Universität (LMU) de Múnich Alemania, concentrados en explorar la cultura escrita de la América colonial, producida sobre todo al margen de la literatura e historiografía clásicas. Algunos de dichos especialistas son los que colaboran ahora en el presente número de Allpanchis. Todos ellos, graduados bajo la asesoría del profesor Wulf Oesterreicher — propulsor del estudio de las tradiciones discursivas y la lingüística variacional-, han venido desarrollando desde hace ya varios años entre sus temas de investigación el seguimiento de las tradiciones del saber europeo llevadas a América durante la cristianización del continente y la evangelización del Perú. Estos estudiosos han puesto especial atención a las relaciones entre el derecho y la catequesis, la conquista y la conversión, el discurso historiográfico y el jurídico; a lo oral en lo escrito; a la «inmediatez comunicativa», a los tópicos temáticos y las tradiciones discursivas presentes en los diferentes géneros y tipos textuales manifestados en textos legales y judiciales, administrativos, historiográficos, eclesiásticos, catequéticos y pastorales, gramáticas y artes de lenguas amerindias, ritos sacramentales, cartas privadas, etc.; y en esta ocasión ofrecen aquí resultados o avances de sus estudios bajo esas líneas de trabajo. En ese sentido, para alcanzar la información a los interesados y especialistas de la manera más sistemática y objetiva, el presente número de Allpanchis se ha dividido en dos partes: una teórica y otra de artículos de casos. La primera comprende dos contribuciones que perfilarán el marco que permitirá ubicar y entender el enfoque de los estudios que siguen.

En general, en las contribuciones que conforman esta edición de Allpanchis se evidencia claramente la atención puesta en tres 
aspectos esenciales al estudio del español en los Andes coloniales. $\mathrm{El}$ primero corresponde a los propios textos escritos, como fuentes primarias de discurso en su sentido más sencillo y como muestras del habla en el amplio espectro del discurso en el interior de un sistema variacional. El aspecto relativo a los autores ha sido también parte esencial de las investigaciones hechas para entender la intención y la funcionalización de los textos. Por último, se ha puesto atención en el estudio del discurso como entidad en la que se ponen de manifiesto las relaciones entre los actos del habla y sus resultados y se acuñan las llamadas «tradiciones discursivas».

En el primer artículo, «El español en los Andes durante la evangelización del Perú colonial desde la perspectiva académica alemana», quien escribe presenta un panorama resumido, a manera de recuento, de las investigaciones y publicaciones hechas por filólogos e investigadores de universidades alemanas en torno al español que se habló y se escribió en los Andes de América, concretamente en el Perú de los siglos XVI y XVII, considerando el ineludible transfondo histórico de la evangelización. El artículo ofrece un panorama que resume la evolución del interés por el tema amerindio y los diferentes enfoques y perspectivas adoptadas en las investigaciones, así como los principales aportes de los más recientes estudios, resaltando los de quienes participan en este número. De ese modo, se espera una mejor comprensión de la línea que siguen las investigaciones particulares de cada colaborador.

Por su parte, el profesor Wulf Oesterreicher, catedrático emérito de la LMU, en la segunda contribución teórica, «La producción textual en español en la América colonial: reflexiones en torno a la “información" y la "autoría”» ofrece una visión de conjunto de la producción de textos en América, concentrándose en el Virreinato del Perú y poniendo de manifiesto cómo las tradiciones discursivas europeas y viejos usos tomaron nuevas formas en los textos americanos al contacto con las nuevas culturas. Esta contribución demuestra que los estudios de las fuentes textuales primarias americanas debe llevarse a cabo considerando dos factores: la 
«información»y la «autoría», como elementos esenciales para perfilar la complejidad de las renovaciones lingüísticas y textuales de la lengua española en el llamado Nuevo Mundo.

La segunda parte de esta edición de Allpanchis comprende cuatro artículos en una secuencia ordenada de acuerdo a la cronología de los documentos que se revisan. El artículo «Elementos etnográficos en la crónica soldadesca del Perú del siglo xvi. La visión del otro», de Eva Stoll, es el análisis de una clase de texto de la historiografía indiana de comienzos de la colonia y poco estudiado: la crónica de soldado. El interés específico en los elementos etnográficos se debe al convencimiento del rol que jugaron en la determinación de la forma y contenido de los textos estudiados. Sobre la base de tres crónicas se busca constatar en qué medida esas obras se relacionan con los criterios de la época en cuanto a las observaciones (aspectos físicos, lenguas, costumbres, religión) que ilustran el encuentro de culturas, y también ver si sus autores siguieron modelos de otros escritores cultos o instrumentalizaron sus escritos de forma particular para algún fin específico.

La siguiente contribución, «Los textos del contacto y el discurso jurídico en los Andes (siglos XVI y XVII)», de Carlos Garatea Grau, es una breve revisión de los fenómenos del contacto de lenguas habidos hasta bien entrado el siglo siguiente, donde el español colonial se puede evidenciar a partir de ejemplos concretos, tomados de textos redactados por bilingües. Se trata de temas y aspectos ya estudiados, que se retoman para resaltar la relevancia del discurso jurídico en el registro del español andino y el carácter heterogéneo del contacto de lenguas. A su vez se ofrecen algunas luces para impulsar la profundización de las observaciones en la obra de Guamán Poma de Ayala.

El estudio de Ulrike Kolbinger, «Testamentos escritos por bilingües en el valle de Jauja (Perú, siglo XVII)», es un análisis del discurso en testamentos elaborados en una etapa avanzada de la evangelización andina por escribanos indios bilingües, oriundos del valle de Jauja, a quienes los nuevos creyentes, pobladores indios, 
confiaron la tarea testamentaria. Es así como dichos documentos se convierten en materia primordial de observación para perfilar su composición y entender las circunstancias en que se produjeron, atendiendo a la competencia jurídica, lingüística y al grado de dominio de las lenguas de contacto de la zona (quechua-castellano) de los escribanos responsables.

Finalmente el artículo de Álvaro Ezcurra Rivero, «Ritmos discursivos y licencias semántico-referenciales: aproximación al sermonario de Fernando de Avendaño (1649)», esboza el perfil de algunas estrategias persuasivas y pedagógicas halladas en la oratoria de Avendaño, concretamente reflejadas en su obra Sermones de los misterios de nuestra santa fé católica, publicada en Lima, en 1649, que tuvieron como trasfondo las campañas de extirpación de las idolatrías. En el artículo se pone atención a dos estrategias, que son analizadas a nivel lingüístico y discursivo recurriendo a ejemplos que ilustran las hipótesis dadas. Esta contribución constituye un aporte a los estudios de la clase textual de los sermones pastorales indianos en el rubro de la oratoria sagrada.

Con la presentación de este panorama, se espera contribuir a la difusión de las líneas de investigación más recientes de la academia alemana y sus seguidores, a partir de una nueva filología abierta al trabajo interdisciplinario. Del mismo modo, se desea con ello motivar la revisión de tantos documentos publicados, o manuscritos inéditos, creados en el marco de la evangelización del Perú colonial, considerando los enfoques aquí expuestos, todavía poco conocidos entre los profesionales de las ciencias humanas en el Perú. Finalmente, quede el agradecimiento especial a la persona de Carlos Zegarra Moretti, sin cuyo apoyo y asesoría durante todo el proceso editorial de este número de Allpanchis no se hubiese podido concretar con éxito tan delicado trabajo. 
